Case Study

\title{
Effects of 2-week intermittent training in hypobaric hypoxia on the aerobic energy metabolism and performance of cycling athletes with disabilities
}

\author{
SAng-Hoon Kim, PhD, $\mathrm{PT}^{1)}$, Ho-Jung An, PhD, $\mathrm{PT}^{2)}$, Jung-Hyun Chol, PhD, $\mathrm{PT}^{3)}$, \\ Yong-Youn KIM, PhD, $\left.\mathrm{PT}^{2}\right)^{*}$ \\ 1) Department of Medical Science, Korea Paralympic Committee, Republic of Korea \\ 2) Department of Physical Therapy, Dongnam Health University: 50 Cheoncheon-ro, 74-Gil, \\ Jangan-gu, Suwon-si, Republic of Korea \\ 3) Department of Physical Therapy, Institute for Elderly Health and Welfare, Namseoul University, \\ Republic of Korea
}

\begin{abstract}
Purpose] The present study aimed at examining changes in aerobic energy metabolism and performance in cycling athletes after 2 weeks of intermittent training in a multistep hypobaric hypoxia environment. [Subjects and Methods] We also aimed at using the findings to propose an efficient training program in hypobaric hypoxia for endurance athletes with disabilities. The study participants were three cycling athletes with physical disabilities from the Korean national team (A, B, and C athletes). They underwent complex (repetition, interval, and continued) training with a roller-type cycle in a multistep hypobaric hypoxia environment (simulated altitude, $4,000 \mathrm{~m}$ above sea level). The training was conducted in twelve 60 -min sessions for 2 weeks and it was based on the ventilatory threshold intensity, measured in an exercise stress test, conducted prior to training, at constant temperature $\left(23{ }^{\circ} \mathrm{C} \pm 2{ }^{\circ} \mathrm{C}\right)$ and humidity conditions $(50 \% \pm 5 \%)$. [Results] $\mathrm{B}$ and $\mathrm{C}$ athletes showed no noticeable changes in relative $\mathrm{VO}_{2}$ max and $\mathrm{HRmax}$ values after training. $\mathrm{A}, \mathrm{B}$, and $\mathrm{C}$ athletes all showed increases in all-out time, $2^{\prime} 09^{\prime \prime}$ (13.1\%), 2'43" (18.7\%), and 1'22" (7.4\%), respectively after training. Although the relative $\mathrm{VO}_{2}$ max and HRmax values were not improved, submaximal exercise performance ability was improved. [Conclusion] Therefore, 2 weeks of intermittent training in a hypobaric hypoxia environment positively affected aerobic energy metabolism and performance.

Key words: Intermittent training in hypobaric hypoxia, Aerobic energy metabolism, Cycling athletes
\end{abstract}

(This article was submitted Jan. 11, 2017, and was accepted Mar. 20, 2017)

\section{INTRODUCTION}

Among various training programs under natural and/or artificial high-altitude environments, one of the most widely used methods is intermittent hypoxic training (IHT), which refers to intermittent training in an artificially hypobaric or normobaric hypoxia environment ${ }^{1}$. Generally, long-term, continuous exposure to a hypoxic environment may cause decreased muscle volume and fiber size by $10-15 \%$ and $20-25 \%$, respectively ${ }^{2,3)}$, as well as reduced citric cycle, oxidation of fatty acids, ketone body utilization, and respiratory enzyme activities ${ }^{4}$. The reasons for preferring IHT in an artificially hypobaric or normobaric hypoxia environment are the easy access to training centers and its being the most efficient method in terms of economic and time aspects ${ }^{5}$.

\footnotetext{
*Corresponding author. Yong-Youn Kim (E-mail: y2kim@hanmail.net)

(C2017 The Society of Physical Therapy Science. Published by IPEC Inc.

This is an open-access article distributed under the terms of the Creative Commons Attribution Non-Commercial No Derivatives (by-nc-nd) License $<$ https://creativecommons.org/licenses/by-nc-nd/4.0/>.
} 
Improvement in oxygen delivery capacity minimizes carbohydrate utilization by decreasing the recruitment of fatty acids that are recruited as an energy source through oxidative phosphorylation, thereby inducing improvement in the corresponding aerobic processes to increase the oxygen utilization ability of mitochondria needed for active muscle contraction and relaxation during submaximal exercise ${ }^{6,7)}$. Moreover, it reduces the accumulation of energy metabolites such as serum lactate, inorganic phosphate $(\mathrm{Pi})$, and ammonia $\left(\mathrm{NH}_{3}\right)$, while bringing about a muscle collagen-saving effect by increasing the energy supply rate from fat metabolism by $\beta$-oxidation ${ }^{8,9)}$. Furthermore, it can also improve the oxygen utilization rate in skeletal muscles by increasing capillary density, the number and size of mitochondria, and tissue myoglobin and 2 , 3-diphosphoglycerate (DPG) concentrations ${ }^{10)}$.

Most of the studies that tested the physiological effects of IHT in an artificially hypobaric or normobaric hypoxia environment examined systemic aspects by examining maximal oxygen consumption $\left(\mathrm{VO}_{2} \mathrm{max}\right)$ and oxygen consumption $\left(\mathrm{VO}_{2}\right)$ under submaximal exercise based on changes in physiological indicators that show oxygen delivery capacity, which include red blood cells $(\mathrm{RBC})$, hemoglobin $(\mathrm{Hb})$, reticulocyte, and erythropoietin $(\mathrm{EPO})^{11,12)}$. The reported findings in these studies have been divided into positive reports of improvement in blood-oxygen delivery capacity and exercise performance capability at sea level and high altitudes, and negative reports of no effect on performance at sea level and no improvement in exercise performance capability, despite changes in blood-oxygen delivery capacity ${ }^{6,13-16)}$. Therefore, the efficiency of IHT in an artificially hypobaric or normobaric hypoxia environment should be analyzed by further dividing the variables that can have an impact on exercise performance capability and performance improvement.

Thus, the present study examined the changes in aerobic energy metabolism and performance from before to after 2 weeks of intermittent training under a multistep hypobaric hypoxia environment for performance improvement in cycling athletes, considering that cycling is one of the most representative aerobic sports, to propose an efficient hypobaric hypoxia training program for endurance athletes with disabilities.

\section{SUBJECTS AND METHODS}

The study participants consisted of three national team cycling athletes with physical disabilities. The purpose and methods of the study were explained to the participant, and informed consent was obtained according to the principles of the Declaration of Helsinki.

In consideration of the originality of the high-altitude environment, a hypobaric hypoxia environment was used as the training environmental condition. The three national team cycling athletes, who had physical disabilities, participated in a complex (repetition, interval, and continued) training with a roller-type cycle in a multistep hypobaric hypoxia environment (from sea level to an altitude of approximately 4,000 m). The training program was conducted in twelve 60-min sessions for 2 weeks and was based on the ventilatory threshold (VT) intensity measured in an exercise stress test conducted prior to the training, at constant temperature and humidity conditions $\left(23{ }^{\circ} \mathrm{C} \pm 2{ }^{\circ} \mathrm{C}, 50 \% \pm 5 \%\right)$. In addition, the participants also underwent pre- and post-training graded maximal exercise stress tests and a 14-km time trial test with a roller-type cycle. The participants were recommended to take iron supplements (40 mg, USA) to increase their blood oxygen delivery capacity. During the training period, the researchers listened to each individual athlete's opinion on the training and daily conditions, and the opinions of instructors on adjusting the training program.

Based on the individual VT intensity $(\mathrm{km} / \mathrm{h})$ measured in a multistep graded maximal exercise stress test at sea level, repetition, interval, and continued training programs, suitable for each simulated altitude in a multistep hypobaric hypoxia environment (simulated altitude, approximately 4,000 $\mathrm{m}$ above sea level), were developed together with a cycling coaching staff, and the exercise intensity was established accordingly. In addition, heart rates (HRs) and workload (speed) during daily training were measured to fine-tune the exercise intensity of each individual athlete at each hypobaric hypoxia environment.

Aerobic energy metabolism was measured in the maximal exercise stress test, performed by each athlete before and after 12 sessions of hypobaric hypoxia training. The protocol used for the maximal exercise stress test was developed in-house by the Sports Science Team at Korea Sports Association for the Disabled, which was developed by taking into account the disability severity and exercise performance level of the athletes. The test was performed after 2 min of warm-up exercise using the following protocol.

The training program consisted of 12 sessions as shown in Table 1. Training intensity and altitude were established based on a discussion with the instructors while considering the athletes' training records and conditions, accumulated daily. The exercise intensity applied in the first session used the results of the maximal exercise stress test, measured prior to the training, and the HR corresponding to VT was set as the target HR (Table 2).

A and B athlete's training was monitored using an arm ergometer. For A, the initial load was set to $25 \mathrm{~W}$ and increased repeatedly every $2 \mathrm{~min}$ by 12 and $13 \mathrm{~W}$ (70 rpm maintained), while for B, the initial load was also set to $25 \mathrm{~W}$ and increased repeatedly every $3 \mathrm{~min}$ by 12 and $13 \mathrm{~W}$ (70 rpm maintained). Meanwhile, C athlete's training was monitored using a cycle ergometer with the initial load set to $100 \mathrm{~W}$ and increased every $2 \mathrm{~min}$ by $25 \mathrm{~W}$ (100 rpm maintained). The tests were performed by continuous gradual increase of the load until the participants reached an all-out state. While the tests at sea level were being conducted during pre- and post-training, an automatic respiratory metabolic system K4b2 (Sensormedics, Italy) was used to measure $\mathrm{HRmax}$, VT-\%HRmax, $\mathrm{VO}_{2} \max , \mathrm{VT}-\% \mathrm{VO}_{2} \mathrm{max}$, and $\mathrm{VT}$ during a graded load maximal exercise for comparing the efficiency of training. 
Table 1. General characteristics

\begin{tabular}{lccc}
\hline Item & A athlete & B athlete & C athlete \\
\hline Age (yrs) & 44 & 45 & 38 \\
Height (cm) & 164.2 & 165.3 & 173.4 \\
Weight (kg) & 66.2 & 54.0 & 67.5 \\
Body mass index & 24.5 & 19.1 & 21.5 \\
Diseases & Spinal cord injury & Spinal cord injury & Brain lesions \\
\hline
\end{tabular}

Table 2. Training program

\begin{tabular}{|c|c|c|c|c|c|}
\hline \multirow{2}{*}{ Sessions } & \multirow{2}{*}{$\begin{array}{l}\text { Training altitude } \\
\text { (pressure) }\end{array}$} & \multicolumn{3}{|c|}{ Mean training intensity, $\mathrm{km} / \mathrm{h}$} & \multirow[t]{2}{*}{ Comments } \\
\hline & & A athlete & B athlete & $\mathrm{C}$ athlete & \\
\hline $1 \mathrm{st}$ & $2,000 \mathrm{~m}$ (596 torr) & 26.0 & 14.2 & 137.6 & Jin - fixed type equipment on day 1 \\
\hline 2nd & $2,000 \mathrm{~m}$ (596 torr) & 25.2 & 14.7 & 30.7 & \\
\hline $3 r d$ & $2,000 \mathrm{~m}$ (596 torr) & 26.0 & 16.2 & 31.3 & \\
\hline 4 th & $2,000 \mathrm{~m}$ (596 torr) & 26.1 & 16.3 & 31.8 & \\
\hline 5 th & $4,000 \mathrm{~m}$ (462 torr) & 24.4 & 13.9 & 31.5 & \\
\hline 6 th & $2,000 \mathrm{~m}$ (596 torr) & 25.8 & 17.0 & 33.5 & \\
\hline 7 th & $2,500 \mathrm{~m}$ (560 torr) & 26.1 & 17.1 & 33.2 & \\
\hline 8 th & $2,500 \mathrm{~m}$ (560 torr) & $26.0 \mathrm{~km} / \mathrm{h}$ & 14.2 & 33.7 & 14-km individual time trial performed together \\
\hline 9 th & $3,000 \mathrm{~m}$ (526 torr) & $25.6 \mathrm{~km} / \mathrm{h}$ & 16.9 & 33.2 & \\
\hline 10 th & $3,000 \mathrm{~m}$ (526 torr) & $24.6 \mathrm{~km} / \mathrm{h}$ & 15.9 & 29.6 & 5-min interval training performed together \\
\hline 11 th & $4,000 \mathrm{~m}$ (462 torr) & $24.4 \mathrm{~km} / \mathrm{h}$ & 14.1 & 33.1 & \\
\hline 12 th & $2,000 \mathrm{~m}$ (596 torr) & $25.3 \mathrm{~km} / \mathrm{h}$ & 16.6 & 33.0 & \\
\hline
\end{tabular}

Performance was measured in 14-km individual time trials conducted before and after training in a location predetermined through discussions with the team coaching staff.

As the data in the present study were acquired from only three participants, inferential statistical analysis was not performed. Instead, the records of each athlete were presented individually.

\section{RESULTS}

Observations on the changes in aerobic energy metabolism from before to after training indicated that the athletes, except $\mathrm{B}$ athlete, showed no noticeable changes in relative $\mathrm{VO}_{2} \mathrm{max}$ and $\mathrm{HRmax}$ values after training. With respect to the all-out time, A, B, and C athletes showed increases of 2'09" (13.1\%), 2'43" (18.7\%), and 1'22" (7.4\%), respectively, after training, respectively. The exercise load during the all-out time increased by $13 \mathrm{~W}(8.0 \%), 12 \mathrm{~W}(16 \%)$, and $25 \mathrm{~W}(9.1 \%)$ after training, respectively. These findings confirmed that although no improvements were observed in the relative $\mathrm{VO}_{2} \mathrm{max}$ and HRmax values of the athletes, their submaximal exercise performance ability, which is attained before reaching the maximal exercise level, did improve.

The records for the 14-km individual time trials from before to after 12 sessions of hypobaric hypoxia training were compared. The results showed that A, B, and C athletes shortened their time by $1^{\prime} 41^{\prime \prime}(5.1 \%), 8^{\prime} 54^{\prime \prime}(16.0 \%)$, and 1'07" $(4.4 \%)$, respectively, which confirmed that all three athletes achieved positive effects in shortening their individual time records through the hypobaric hypoxia training used in the present study (Tables 3 and 4).

\section{DISCUSSION}

During the maximal exercise stress tests, the comparison between the pre- and post-training relative $\mathrm{VO}_{2}$ values under the same load condition (watts) showed a decrease in the relative $\mathrm{VO}_{2}$ value of A athlete, which indicated an improvement in exercise efficiency for performing exercise under the same load condition (watts). Although the present study could not make a direct determination on such physiological changes, we believe that these changes may be attributable to the short 2-week hypobaric hypoxia training, which resulted in increased activation and ventilation from improved oxidative phosphorylation reaction, and increased mitochondria and capillary density, which in turn led to the increased aerobic energy supply rate 
Table 3. The changes in aerobic energy metabolism from before to after 12 sessions of hypobaric hypoxia training

\begin{tabular}{lccccccccc}
\hline \multirow{2}{*}{ Categories } & \multicolumn{3}{c}{ A athlete } & \multicolumn{3}{c}{ B athlete } & \multicolumn{3}{c}{ C athlete } \\
\cline { 2 - 10 } & Pre & Post & Change & Pre & Post & Change & Pre & Post & Change \\
\hline $\mathrm{VO}_{2} \max (\mathrm{ml} /[\mathrm{kg} \cdot \mathrm{min}])$ & 46.0 & 37.0 & -9 & 29.0 & 28.0 & -1 & 57.3 & 58.5 & +1.2 \\
$\mathrm{HRmax}(\mathrm{bpm})$ & 185.5 & 183.0 & -2.5 & 162.7 & 163.0 & +0.3 & 179.7 & 179.4 & -0.3 \\
All-out time & $221-\mathrm{ou}$ & $251-\mathrm{ou}$ & $+21-\mathrm{ou}$ & $121-\mathrm{ou}$ & $151-\mathrm{ou}$ & $+21-\mathrm{ou}$ & $161-\mathrm{ou}$ & $171-\mathrm{ou}$ & $+11-\mathrm{ou}$ \\
Maximum exercise intensity (W) & 162 & 175 & +13 & 75 & 87 & +12 & 275 & 300 & +25 \\
\hline
\end{tabular}

Table 4. The 14-km individual time trials from before to after 12 sessions of hypobaric hypoxia training

\begin{tabular}{lccccccccc}
\hline \multirow{2}{*}{ Category } & \multicolumn{3}{c}{ A athlete } & \multicolumn{3}{c}{ B athlete } & \multicolumn{2}{c}{ C athlete } \\
\cline { 2 - 10 } & Pre & Post & Change & Pre & Post & Change & Pre & Post & Change \\
\hline 14-km time trial & 331 tim & 311 tim & -11 tim & 551 tim & 461tim & -861 tim & 25ltim & 241 tim & -141 tim \\
\hline
\end{tabular}

that decreased lactic acid production, causing the delay in $\mathrm{pH}$ reduction ${ }^{2,5,7)}$. Metabolic acidosis, which appears in the later stage of such adaptive exercise, was delayed, and the activation energy required for ATP regeneration was reduced to induce consumption of less oxygen during exercise under equivalent intensity ${ }^{17,18}$.

Among the maximal exercise stress test results of A athlete, a comparison between the pre- and post-training HRs under the same load condition (watts) showed that the HR decreased after training for all load conditions. As explained earlier, this was due to the decrease in blood flow requirement from the improved oxygen supply and utilization efficiency, which led to decreased HR or increased tidal volume ${ }^{2,5,7)}$. However, considering that the training program used in the present study consisted of 12 sessions conducted over 2 weeks, the decrease in blood flow due to the increased oxygen supply and utilization efficiency may have played a bigger role ${ }^{11,17,18)}$.

In the comparison between the pre- and post-training relative $\mathrm{VO}_{2}$ values under the same load condition (watt), $\mathrm{B}$ athlete did not show any difference up to $37 \mathrm{~W}$, after which the relative $\mathrm{VO}_{2}$ values decreased owing to the training. Moreover, among the maximal exercise stress test results of $\mathrm{B}$ athlete, a comparison of the pre- and post-training HRs under the same load condition (watts) showed that the HR decreased after training for all load conditions at $>37 \mathrm{~W}$. We believe that such changes may be attributed to the same reasons given earlier for $\mathrm{A}$ athlete.

In the comparison between the pre- and post-training relative $\mathrm{VO}_{2}$ values under the same load condition (watts), $\mathrm{C}$ athlete showed an overall decrease after training. Moreover, among the maximal exercise stress test results of $\mathrm{C}$ athlete, a comparison of the pre- and post-training HRs under the same load condition (watts) also showed decreases for all submaximal load conditions.

Considering that no major changes were found in the relative $\mathrm{VO}_{2}$ max and $\mathrm{HRmax}$ values and that the training program in the present study consisted of 12 sessions conducted over 2 weeks, we believe that the program was too short to promote changes in maximal exercise capacity. A study by Sun et al. ${ }^{19)}$ on national reserve fin swimming team members reported that 2 weeks of hypobaric hypoxia training of the athletes resulted in no changes in maximal exercise capacity, which supports the findings in the present study. However, increases in the time required to reach maximal exercise level and decreases in oxygen consumption and HR during exercise under the same load condition from 12 sessions of hypobaric hypoxia training were also identified in a study by Sun et al. ${ }^{19)}$, which are believed to be the effects of short-term hypobaric hypoxia training, as in the present study. In the comparison of athlete performance from before to after hypobaric hypoxia training, the results confirmed the positive effects of the training program in all three athletes, with shortened time trial results.

Schmidt et al. reported ${ }^{20)}$ that $\mathrm{Hb}$ level in cycling athletes increased after living at an altitude of 2,600 m, while Lundby et al. reported that when 8 trained men were exposed to an altitude of $4,100 \mathrm{~m}$ for $2 \mathrm{hr}$ a day, every day for 14 days, no changes in $\mathrm{Hb}$, hematocrit, reticulocyte, serum transferrin receptor, and EPO level were observed, but their $\mathrm{VO}_{2}$ max increased ${ }^{16)}$. Meanwhile, Brugniaux et al. ${ }^{11)}$ conducted a Living High Training Low program among 20 elite medium/long-distance track athletes, which involved running 1,200 m after exposure or $14 \mathrm{hr}$ per day to an altitude of 2,500 $\mathrm{m}$ in the first 6 days and $3,000 \mathrm{~m}$ in the remaining 12 days, for a total of 18 days. The results showed increased $\mathrm{VO}_{2}$ max and peak aerobic power but reduced HR during exercise at $19.5 \mathrm{~km} / \mathrm{hr}$. Moreover, this effect was reported to last for 15 days. Therefore, we believe that such results were due to the positive changes in aerobic energy metabolism in the study participants.

This study has several limitations to be considered for the future studies. First, since this study observed handicapped athletes, the findings of this study cannot be extended and applied to the normal subjects. Second, since this study was a case study without controls, future studies should compare the findings with normal subjects as controls. Third, the findings of this study may not be generalized since the study was conducted with limited duration and subjects. Therefore, complementary measures should be considered for the future studies which include greater number of subjects, mid to long-term study duration, and comparative controls as subjects. 


\section{REFERENCES}

1) Faiss R, Girard O, Millet GP: Advancing hypoxic training in team sports: from intermittent hypoxic training to repeated sprint training in hypoxia. Br J Sports Med, 2013, 47: i45-i50. [Medline] [CrossRef]

2) Green HJ, Roy B, Grant S, et al.: Increases in submaximal cycling efficiency mediated by altitude acclimatization. J Appl Physiol 1985, 2000 , 89: 1189-1197. [Medline]

3) MacDougall JD, Green HJ, Sutton JR, et al.: Operation Everest II: structural adaptations in skeletal muscle in response to extreme simulated altitude. Acta Physiol Scand, 1991, 142: 421-427. [Medline] [CrossRef]

4) Howald H, Pette D, Simoneau JA, et al.: Effect of chronic hypoxia on muscle enzyme activities. Int J Sports Med, 1990, 11: S10-S14. [Medline] [CrossRef]

5) Levine BD: Intermittent hypoxic training: fact and fancy. High Alt Med Biol, 2002, 3: 177-193. [Medline] [CrossRef]

6) Robach P, Schmitt L, Brugniaux JV, et al.: Living high-training low: effect on erythropoiesis and aerobic performance in highly-trained swimmers. Eur J Appl Physiol, 2006, 96: 423-433. [Medline] [CrossRef]

7) Saunders PU, Telford RD, Pyne DB, et al.: Improved running economy in elite runners after 20 days of simulated moderate-altitude exposure. J Appl Physiol 1985, 2004, 96: 931-937. [Medline] [CrossRef]

8) Brooks GA, Wolfel EE, Groves BM, et al.: Muscle accounts for glucose disposal but not blood lactate appearance during exercise after acclimatization to 4,300 m. J Appl Physiol 1985, 1992, 72: 2435-2445. [Medline]

9) Wolfel EE, Groves BM, Brooks GA, et al.: Oxygen transport during steady-state submaximal exercise in chronic hypoxia. J Appl Physiol 1985, 1991, 70: 1129-1136. [Medline]

10) Schobersberger W, Tschann M, Hasibeder W, et al.: Consequences of 6 weeks of strength training on red cell $\mathrm{O}_{2}$ transport and iron status. Eur J Appl Physiol Occup Physiol, 1990, 60: 163-168. [Medline] [CrossRef]

11) Brugniaux JV, Schmitt L, Robach P, et al.: Living high-training low: tolerance and acclimatization in elite endurance athletes. Eur J Appl Physiol, 2006, 96: 66-77. [Medline] [CrossRef]

12) Roberts AC, Butterfield GE, Cymerman A, et al.: Acclimatization to 4,300-m altitude decreases reliance on fat as a substrate. J Appl Physiol 1985, 1996, 81: 1762-1771. [Medline]

13) Balke B, Faulkner JA, Daniels JT: Maximum performance capacity at sea-level and at moderate altitude before and after training at altitude. Schweiz Z Sportmed, 1966, 14: 106-116. [Medline]

14) Terrados N, Melichna J, Sylvén C, et al.: Effects of training at simulated altitude on performance and muscle metabolic capacity in competitive road cyclists. Eur J Appl Physiol Occup Physiol, 1988, 57: 203-209. [Medline] [CrossRef]

15) Gore CJ, Hahn AG, Aughey RJ, et al.: Live high: train low increases muscle buffer capacity and submaximal cycling efficiency. Acta Physiol Scand, 2001, 173: 275-286. [Medline] [CrossRef]

16) Lundby C, Nielsen TK, Dela F, et al.: The influence of intermittent altitude exposure to $4,100 \mathrm{~m}$ on exercise capacity and blood variables. Scand J Med Sci Sports, 2005, 15: 182-187. [Medline] [CrossRef]

17) Sun WS, Hwang KS: Effects of chronic intermittent hypobaric hypoxic training on cardiopulmonary function and oxygen transporting capacity in trained athletes. Kor J Phys Edu, 2004, 43: 441-455.

18) Shin CH, Cho SY: Effects of intermittent hypoxic training on cardiopulmonary function and blood parameter in elite swimmer. Exer Sci, 2003 , 12 : 223-231.

19) Sun OS, Nho HS, Nam SS: The effects of intermittent hypobaric hypoxic training at the stimulated altitude of 3,000 $\mathrm{M}$ on aerobic exercise performance in youth fin swimmer. J Phys Grow Mot Dev, 2007, 15: 241-249.

20) Schmidt W, Dahners HW, Correa R, et al.: Blood gas transport properties in endurance-trained athletes living at different altitudes. Int J Sports Med, 1990, 11: 15-21. [Medline] [CrossRef] 